Available online at GSC Online Press Directory

GSC Biological and Pharmaceutical Sciences

e-ISSN: 2581-3250, CODEN (USA): GBPSC2

Journal homepage: https://www.gsconlinepress.com/journals/gscbps

(RESEARCH ARTICLE)

\title{
Antimicrobial susceptibility pattern of urinary isolates from outpatients suspected for urinary tract infection
}

\author{
Ezenobi Nkechi Obiofu *, Ogbu Hanson Ige and Onosigho Iroro \\ Department of Pharmaceutical Microbiology and Biotechnology, Faculty of Pharmaceutical Sciences, University of Port \\ Harcourt, Choba P.M.B.5323, Port Harcourt, Rivers State, Nigeria.
}

Publication history: Received on 25 October 2018; revised on 16 November 2018; accepted on 20 November 2018

Article DOI: https://doi.org/10.30574/gscbps.2018.5.3.0124

\begin{abstract}
Urinary tract infection (UTI) is one of the most common bacterial infections in humans and a major cause of morbidity. The pathogens traditionally associated with UTI and their antibiotic sensitivity patterns are changing from time to time and across different environment. Knowledge of the antibiotic resistance patterns of uropathogens in specific geographical locations is an important factor for choosing an appropriate empirical antimicrobial treatment. This study therefore evaluates the causative organisms present in urine specimen and their antibiotic susceptibility profile among patients suspected for UTI attending the general outpatient department clinic of the University of Port Harcourt Teaching Hospital, Nigeria. One hundred and fifty (150) mid-stream urine samples were collected from patients suspected of having a UTI and subjected to macroscopic assessment, isolation, and characterization as well as resistance- susceptibility test of isolates using standard conventional techniques. Results showed that UTI was frequently encountered in females 39 (26\%) than males 21 (14\%) while $60 \%$ of the samples yielded no growth after 48 hours incubation. The most common pathogens isolated were Staphylococcus aureus (47.19\%), followed by Escherichia coli (20.22\%), Klebsiella pneumoniae (15.73\%), Candida albicans (10.11\%), Pseudomonas aeruginosa (5.62\%) and Proteus mirabilis (1.12\%). Staphylococcus aureus isolates were highly susceptible to Amoxicillin/Clavulanate (88.10\%) with lower susceptibility to Ofloxacin (52\%), Cloxacillin (50\%). This information will directly affect selection of empirical therapy for UTI and emphasizes the need for choosing an appropriate antimicrobial treatment in specific geographical locations.
\end{abstract}

Keywords: Urinary tract infection; Pathogens; Susceptibility; Resistance; Antimicrobial; Etiology

\section{Introduction}

Urinary tract infections (UTIs) consists of microbial invasion and multiplication in any of the structures of the urinary system with attendant signs of inflammation. Terms such as significant bacteriuria, asymptomatic bacteriuria, cystitis, urethral syndrome, acute or chronic pyelonephritis have also been used to describe this infection [1]. Infection may occur at any part of the genitourinary tract, including urethra, bladder, ureter, renal pelvis, or renal parenchyma [2]. This tract collects and stores urine and provides the urinary system of tubes necessary to release it from the body.

UTI can be asymptomatic or symptomatic, characterized by a wide spectrum of symptoms ranging from mild irritative voiding to bacteremia, sepsis or even death. Other major symptoms may include: strong urge to urinate frequently, even immediately after the bladder is emptied (Urgency), painful burning sensation when urinating (Dysuria), discomfort, pressure, or bloating in the lower abdomen, pain in the pelvic area or back, cloudy or bloody urine (Haematuria), which may have a strong smell, urination during the night (Nocturia), frequent urination (Polyuria) [3].

\footnotetext{
${ }^{*}$ Corresponding author

E-mail address: nkechi.ezenobi@uniport.edu.ng
}

Copyright (C) 2018 Author(s) retain the copyright of this article. This article is published under the terms of the Creative Commons Attribution Liscense 4.0. 
UTI represents one of the most common diseases encountered in medical practice today with an estimated 150 million UTIs per annum worldwide [4]. Although UTIs occur in both men and women, studies suggest that the overall prevalence of UTI is higher in women due to their anatomy [5,6]. Some factors that may contribute to urinary tract infections are, structure of the female urinary tract, sexual intercourse, irregular urination, birth control methods, inadequate personal hygiene, history of previous UTIs, insufficient water intake, catheters or tubes placed in the bladder $[6,7]$. While up to $90 \%$ of the patients with UTIs complain of urinary tract symptoms, one third or more of the patients with these symptoms do not have bacteriuria [8]. The most common symptoms for which most patients seek treatment are dysuria and frequency. Dysuria and frequency together raise the probability of UTI to more than $90 \%$, effectively ruling in the diagnosis by history alone [9]. The etiology of UTI is related to the great diversity of microbial invaders, such as: bacteria, viruses and fungi. According to Ramesh et al. [10] bacteria are the major causative organism and are responsible for more than $95 \%$ of UTI cases. Several studies on the prevalence of bacterial isolates from suspected urinary tract infection patients have shown that the commonest isolates were species of Escherichia, Staphylococcus, Klebsiella, Pseudomonas and Proteus [11-16]. In acute uncomplicated UTI acquired in the community, Escherichia coli, is by far the most common causative bacteria being responsible for about 80 percent of infections [11, 17, 18]. The remaining 20 percent is caused by other gram-negative enteric bacteria such as Klebsiella and Proteus species, and by gram positive cocci particularly Enterococci and Staphylococcus saprophyticus [11]. In all Gram-negative isolates formed a major constituent of bacterial uropathogens [11].

Antibiotics usually are the first line treatment for urinary tract infections. However, treatment is often started empirically, and therapy is based on information determined from the antimicrobial resistance pattern of the urinary pathogens [19]. The commonly prescribed ones include Levofloxacin, Ciprofloxacin, Cephalexin, Trimethoprim/ sulfamethoxazole, Nitrofurantoin, Fosfomycin, Trimethoprim and Nalidixic acid [12, 15, 20]. Unfortunately, the extensive use of these antimicrobial agents has invariably resulted in the development of antibiotic resistance, which, has now become a major problem worldwide [21-23]. The increase in multidrug resistance in bacterial uropathogens is an important and evolving public challenge [24, 25]. The etiology of UTI and antibiotic resistance of uropathogens have been changing over past years, both in community and nosocomial infection [26-28]. Although several susceptibility testing studies have been undertaken, but not much seems to have been done on the resistance pattern of community acquired UTI pathogens. This study therefore evaluates the causative organisms present in urine specimen and their antibiotic susceptibility profile among patients suspected for UTI attending the General Outpatient department (GOPD) clinic of the University of Port Harcourt Teaching Hospital, Nigeria. The area-specific monitoring studies aimed at gaining knowledge about the type of pathogens responsible for urinary tract infections and their resistance patterns may help the clinician make inform decisions as previously reported [29].

\section{Material and methods}

\subsection{Sample population, collection and processing}

The study population was drawn from patients suspected for urinary tract infection and attending the General Outpatient Department (GOPD) clinic, University of Port Harcourt Teaching Hospital, Rivers State. A total of one hundred and fifty (150) early morning mid-stream urine specimens were collected, in sterile, dry, wide-mouth leak proof containers. The samples were labeled and transported immediately to pharmaceutical microbiology laboratory, University of Port Harcourt for examination.

\subsection{Ethical considerations}

This study was approved by the research and ethics committee of University of Port Harcourt Teaching Hospital, Rivers State. All samples were collected following voluntary informed consent of the participants and in some cases, their legal guardian. All patient's data and bacterial isolates gathered in this study were handled confidentially and in accordance with approved protocols of handling patient data.

\subsection{Macroscopic examination of urine}

The urine samples were physically examined by swirling or inverting the bottles for the presence or absence of cloudiness or turbidity. Turbidity would indicate the presence of bacteria, proteins, crystals, leucocytes, precipitation of urates (acids) or phosphates and carbonates (alkaline).

\subsection{Urine culture}

Using a standard wire loop, a loopful of each urine sample was inoculated on to Cystine Lactose Electrolyte Deficient (CLED) agar (a non-selective medium capable of supporting the growth of most urinary pathogens and giving good 
colonial differentiation without spread of Proteus spp) (Lab M limited, U.K), and incubated at $37{ }^{\circ} \mathrm{C}$ for 24 hours [30]. Plates that showed significant growth were selected and the colonies aseptically isolated and sub-cultured onto Mannitol Salt Agar (Lab M limited, U.K), MacConkey Agar (Lab M limited, U.K), Sabouraud Dextrose Agar or Cetrimide agar and incubated at $37^{\circ} \mathrm{C}$ for $24-48$ hours.

\subsection{Identification of isolates}

After overnight incubation at $37{ }^{\circ} \mathrm{C}$ for $24-48$ hours colonies were identified and characterized using colony characteristics, gram reaction of the organisms and biochemical test following standard procedure [31].

\subsection{Antibiotic sensitivity testing}

Sensitivity testing was performed following modified Kirby-Bauer disc diffusion method as recommended by National Committee for Clinical Laboratory Standards (NCCLs) [32]. Discs containing the following antibacterial agents were used: Amoxicillin/Clavulanate $30 \mu \mathrm{g}$, Ofloxacin $5 \mu \mathrm{g}$, Ciprofloxacin $5 \mu \mathrm{g}$, Gentamicin $10 \mu \mathrm{g}$, Cefuroxime $30 \mu \mathrm{g}$, Ceftazidime $30 \mu \mathrm{g}$, Ampicillin $10 \mu \mathrm{g}$, Nitrofurantoin $300 \mu \mathrm{g}$ against gram negative bacteria and Amoxicillin/Clavulanate $30 \mu \mathrm{g}$, Ofloxacin $5 \mu \mathrm{g}$, Cloxacillin $5 \mu \mathrm{g}$, Erythromycin $5 \mu \mathrm{g}$, Ceftriaxone $30 \mu \mathrm{g}$, Gentamicin $10 \mu \mathrm{g}$, Cefuroxime $30 \mu \mathrm{g}$, Ceftazidime $30 \mu \mathrm{g}$ against gram positive bacteria. Standard Ketoconazole solution (0.25\%) was tested against Candida albicans. The plates were incubated at $37^{\circ} \mathrm{C}$ for 24 hours after which the zones of inhibition were measured in millimeter. Using the interpretative chart derived from the zones of inhibition of Standard organisms according to the Clinical Laboratory Science Institute (CLSI), the zone size of each antimicrobial agent was interpreted [32].

\subsection{Statistical analysis}

Data collected were entered into Microsoft excel spreadsheet and analysed using T-test, Anova (Single factor) to calculate probabilities and determine significance. A p-value of less than or equal to $0.05(\mathrm{p} \leq 0.05)$ is considered to be statistically significant [22].

\section{Results}

\subsection{Isolation and identification of isolates}

Out of the 150 samples obtained from the patients suspected for UTI, 60 samples (40\%) were found to contain heavy and appreciable bacterial growth (significant bacteriuria) while $90(60 \%)$ had no appreciable bacterial growth (Figure 1). From the 60 samples investigated, 89 isolates were recovered with females having a greater percentage of occurrence 39 (26\%) than males 21 (14\%).The predominant isolate was Staphylococcus aureus constituting 42 (47.19\%) of the total isolates followed by Escherichia coli 18 (20.22\%), Klebsiella pneumoniae 14 (15.73\%), Pseudomonas aeruginosa 5 (5.62\%) and Proteus mirabilis 1 (1.12\%). Fungal isolate as Candida albicans accounted for 9 $(10.11 \%)$ and the result presented in Figure 2.

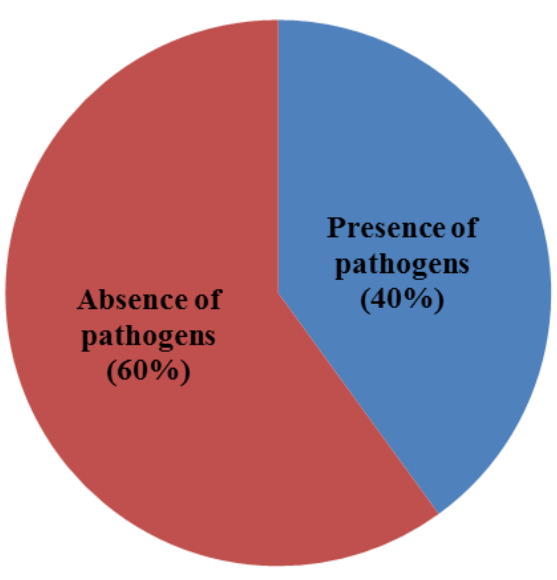

Figure 1 Percentage distribution for primary isolation of causative agents 


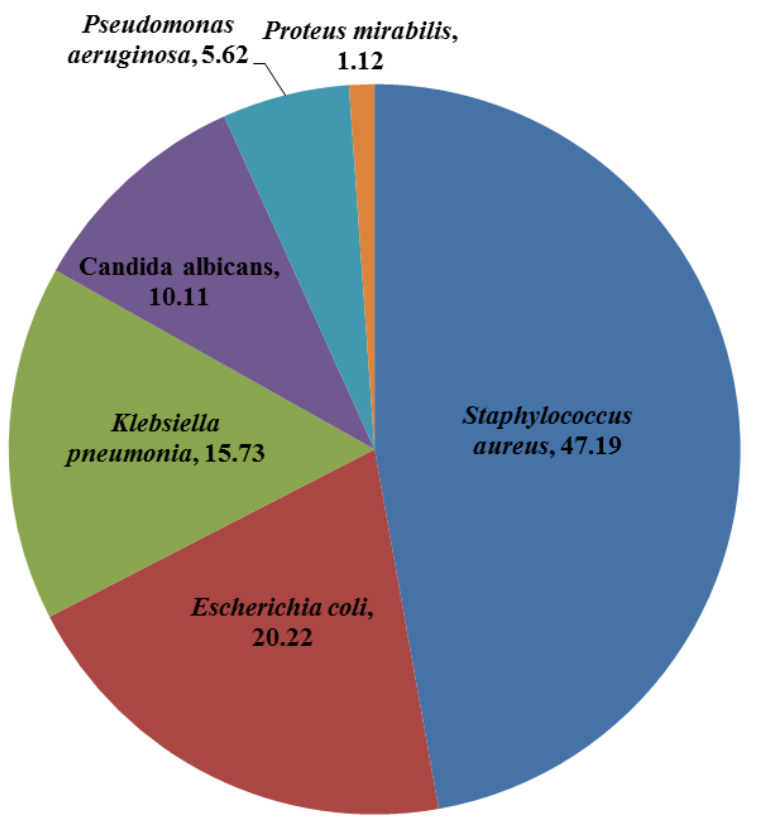

Figure 2 Percentage distribution of urinary isolates from samples

\subsection{Antimicrobial susceptibility test}

In-vitro sensitivity test for antimicrobial agents on Muller Hinton agar using the Kirby-Bauer disk diffusion method were carried out for the representative isolates, which include Gram-positive organism, Gram-negative organisms and fungi organism. The antibiotic susceptibility test results show that the Gram-positive organism (Staphylococcus aureus), are susceptible to Amoxicillin/Clavulanate (52.38\%), Ofloxacin (52\%) and Cloxacillin (45.24\%) (Figure 3). The Gramnegative organisms were highly susceptible to Nitrofurantoin than other antibiotics used (Figures 4 - 7) while Candida albicans $(77.78 \%)$ showed a good susceptibility to Standard Ketoconazole (Figure 8). Generally, there was a notable resistance to Amoxicillin/Clavulanate and Ampicillin.

\section{S. aureus}

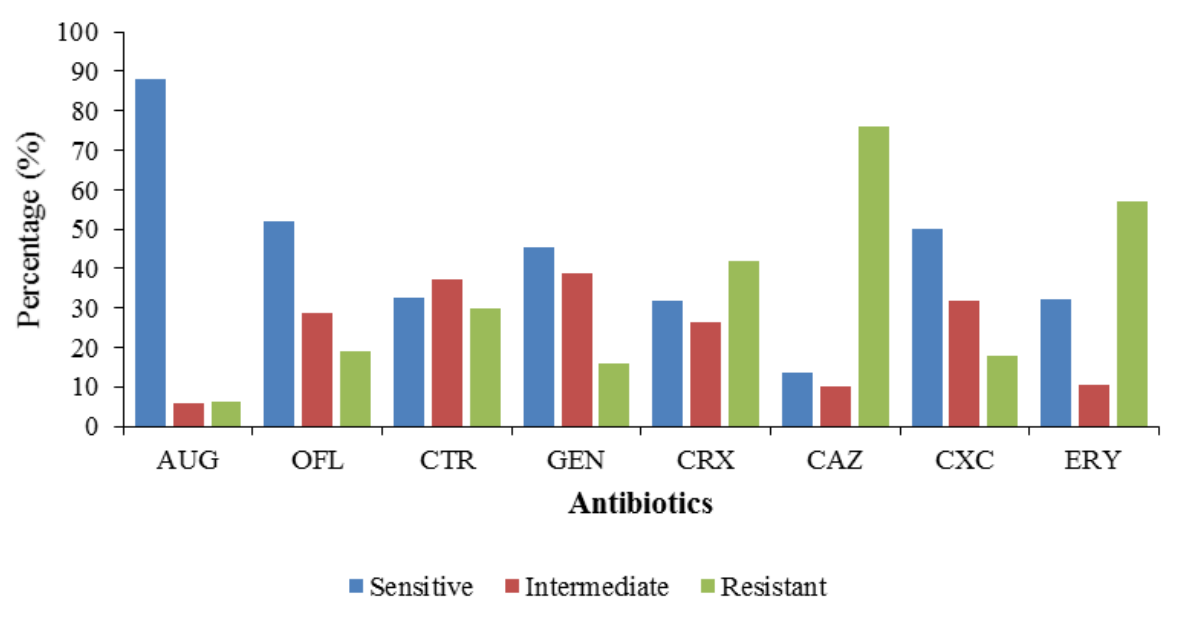

Figure 3 Antimicrobial susceptibility test for Staphylococcus aureus

$\mathrm{AUG}=$ Amoxicillin/Clavulanic acid, OFL= Ofloxacin, $\mathrm{CTR}=$ Ceftriaxone, GEN= Gentamicin, $\mathrm{CRX}=$ Cefuroxime, $\mathrm{CAZ}=$ Ceftazidime, $\mathrm{CXC}=\mathrm{Cloxacillin}$, ERY= Erythromycin 


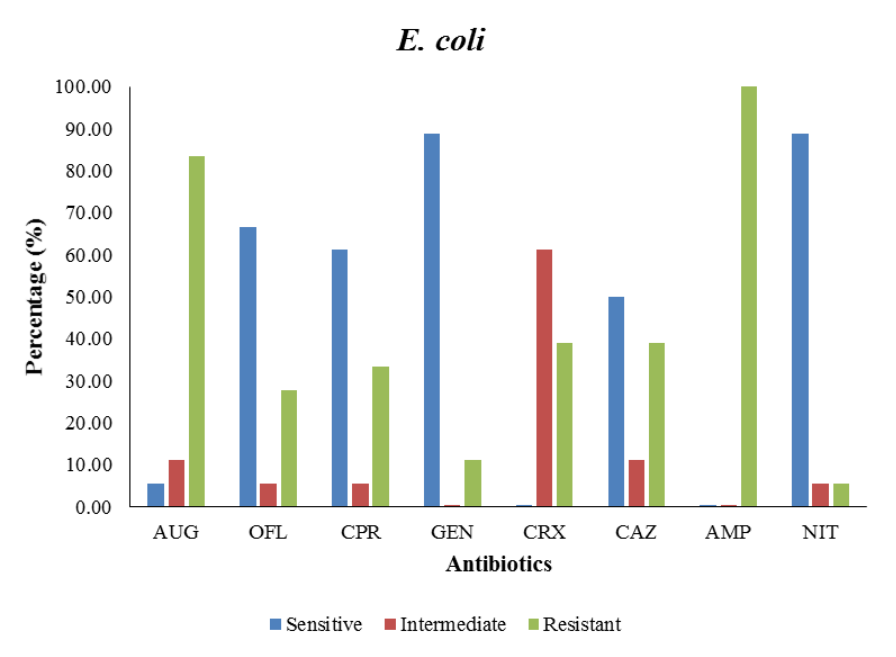

Figure 4 Antimicrobial susceptibility test for Escherichia coli

$\mathrm{AUG}=$ Amoxicillin/Clavulanic acid, $\mathrm{OFL}=$ Ofloxacin, $\mathrm{CPR}=$ Ciprofloxacin, $\mathrm{GEN}=$ Gentamicin, $\mathrm{CRX}=$ Cefuroxime, $\mathrm{CAZ}=\mathrm{Ceftazidime}, \mathrm{AMP}=\mathrm{Ampicillin}$, NIT $=$ Nitrofurantoin

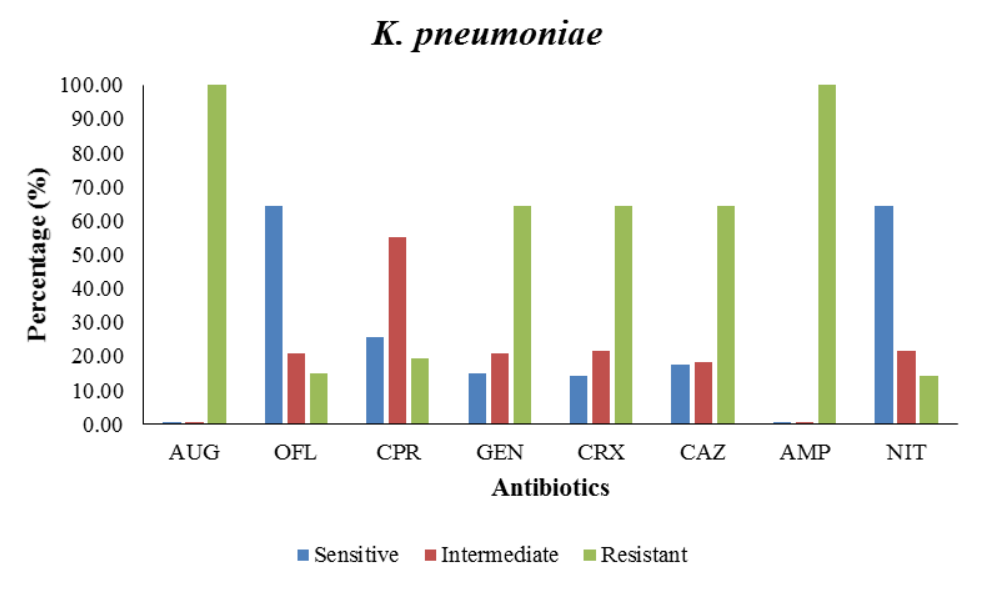

Figure 5 Antimicrobial susceptibility test for Klebsiella pneumoniae

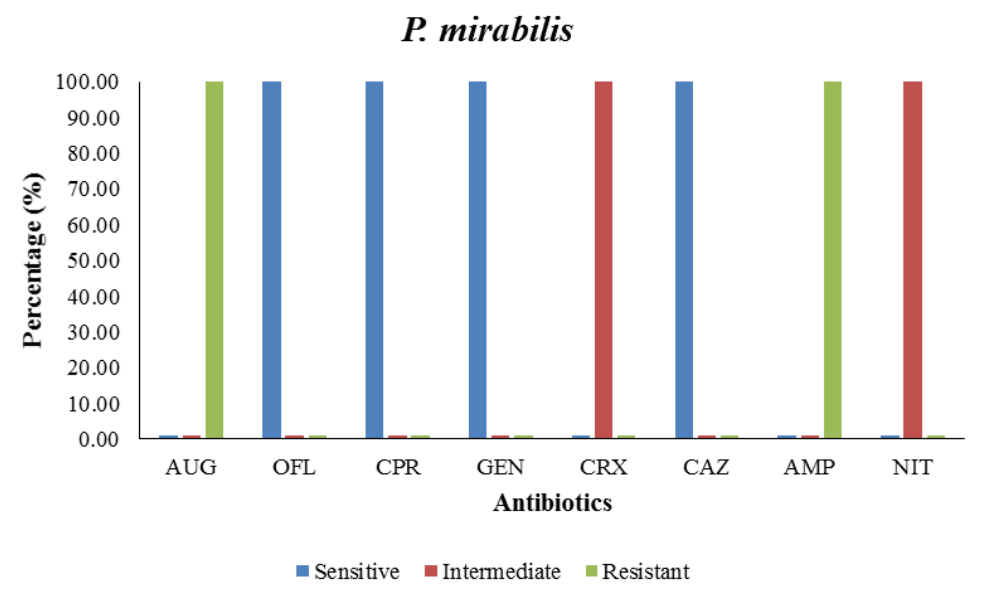

Figure 6 Antimicrobial susceptibility test for Proteus mirabilis 


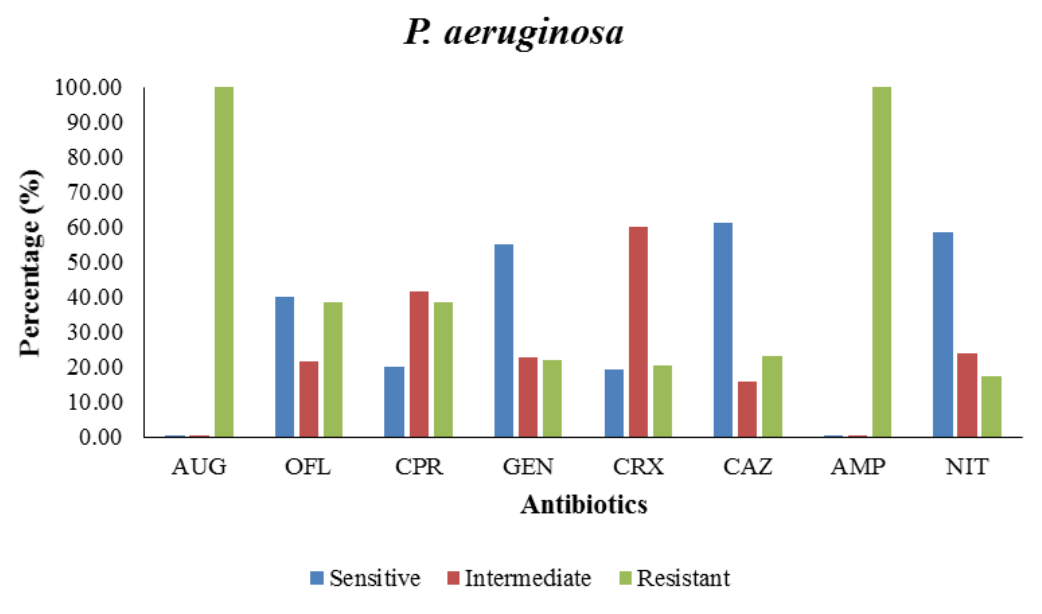

Figure 7 Antimicrobial susceptibility test for Pseudomonas aeruginosa

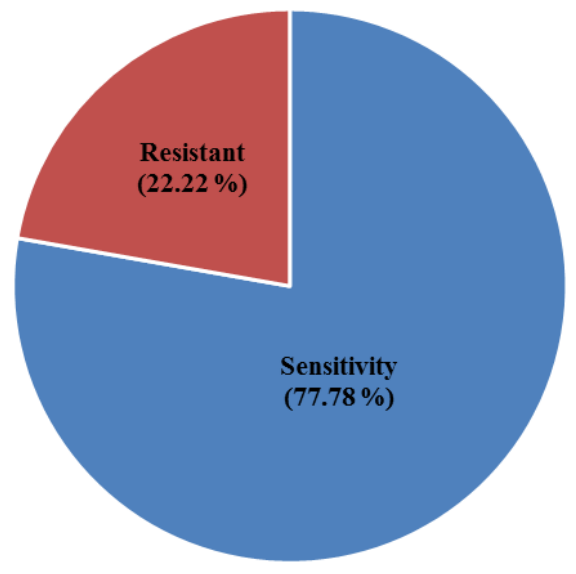

Figure 8 Susceptibility of Candida albicans to Ketoconazole $(0.25 \mu \mathrm{g})$

\section{Discussion}

\subsection{Prevalence of commonly isolated urinary pathogens}

This study presents the microbiological examination of urine samples of 150 outpatients that fall within the age group of 15 to above 66 years. The results of the study have shown the incidence of asymptomatic urinary tract infection in this population to be $40 \%$. The most predominant bacterial isolate from the urine samples is Staphylococcus aureus (47.19\%) followed by Escherichia coli (20.22\%), Klebsiella pneumoniae (15.73\%), Pseudomonas aeruginosa (5.62 \%) and Proteus mirabilis (1.12 \%). Fungal isolate as Candida albicans accounted for (10.11\%). This finding is similar to previous reports showing Gram-positive bacteria, particularly $S$. aureus as the most commonly implicated pathogen in patients with UTIs [33]. This could be as a result of its minimal growth requirements, ability to survive long in most unfavourable environments and to find a susceptible host. Akortha and Ibadin [33] previously noted the high incidence of $S$. aureus possibly due to the virulent nature of the organism, which gives it the ability to overcome body defense mechanisms and resistance to antibiotics. Earlier reports seem to suggest $S$. aureus as the most frequently isolated organism as well as the leading etiologic agent in urinary tract infection in our environment [34, 35]. It constituted as high as $28.09 \%$ of cases in women suspected of UTI compared to men (19.1\%) and in agreement with the findings presented by Abdul and Onile [36] showing UTI caused by S. aureus as the most common among women in Ilorin, Northcentral, Nigeria. The high incidence of $S$. aureus in women could be due to the proximity between the genital tracts and the urethra/anus, which perhaps facilitate auto transmission as earlier reported [37].

Escherichia coli was recorded as the second prevalent isolate in this study, but fails to agree with previous report on uropathogens showing E. coli as the most frequently isolated organism in patients with UTIs [38, 39]. The high incidence of $E$. coli is attributed to the fact that it is a commensal of the bowel and infection is mostly through faecal contamination 
occasioned by poor hygiene. Also, improper wiping after urination or defecation can result in transfer of organisms from the anus to the distal urethra. Previous studies on children hospitalized for non-infective urinary tract diseases shows Klebsiella species as the most frequently isolated organism, closely followed by $S$. aureus [40]. Samples obtained from students and commercial sex workers in Zaria, North-central, Nigeria showed prevalence of P. aeruginosa (53.4 \%), S. aureus (43.3\%) and E. coli (40.7\%). As expected the commercial sex workers had the highest (30.6\%) prevalence of bacteria in their urine samples while the students had the least [41].

As shown in this study, Candida albicans was the fourth prevalent isolate in contrast to earlier report by Richards et al. [42] describing nosocomial infections in medical intensive care units. In their report, however, C. albicans was the most common single pathogen isolated from urine and these infections were associated with asymptomatic funguria rather than symptomatic urinary tract infections. Similar study on fungal urinary tract infection in patients at risk (such as severely ill patients, those with chronic renal failure, diabetes mellitus among others) Krcmery et al. [43] showed $C$. albicans as the most commonly isolated pathogen, followed by non-albicans Candida species (Candida tropicalis, Candida krusei) and then non- yeast Candida yeasts (Blastoschizomyces capitatus). The infection by this pathogen was reported to be associated with device use, fungal infections with urinary catheters.

\subsection{Antimicrobial susceptibility}

The knowledge of antibiotic susceptibility patterns of bacterial pathogens is essential to guide empirical and pathogen specific therapy [44]. As shown during the susceptibility testing, Amoxicillin/Clavulanate (88.1\%) was the most active against $S$. aureus, followed by the Fluoroquinolones in the following order Ofloxacin (52\%), Cloxacillin (50\%) and Gentamicin (45.2\%). The organism showed high resistance to Ceftazidime (76.2\%) and Erythromycin (57.14 \%). Earlier studies in which similar antibiotics were used, indicates that S. aureus was sensitive to Amoxicillin/Clavulanate, Ofloxacin, Gentamicin, Cefuroxime, Erythromycin and resistant to Co-trimoxazole, Tetracycline and Nalidixic acid [33, 45]. Sensitivity patterns of $S$. aureus to antibiotics reported by Shittu and Mandere [46] showed slight contrast with a $100 \%$ sensitivity to gentamicin and cephalosporin, but resistant to Amoxicillin/Clavulanate and Nitrofurantoin. These differences in sensitivity pattern of $S$. aureus could be attributed to environmental factors such as the misuse and abuse of antibiotics among the general population, which has favoured the emergence of resistance strains.

The susceptibility test of $E$. coli shows that Gentamicin and Nitrofurantoin (88.89\%) are active against the isolate, followed by Ofloxacin (66.67\%), Ciprofloxacin (61.11\%), Ceftazidime (50\%). The Nitrofurantoin demonstrated better activity against $E$. coli isolates probably because it is well absorbed orally and is rapidly excreted in the urine so that drug levels in urine are high while serum levels are minimal [47] E. coli was highly resistant to Ampicillin (100\%) and Amoxicillin/Clavulanate (83.33\%) and in agreement with previous studies [15, 48-51]. Asides resistance, the beta ( $\beta$ )lactam antibiotics are known to have relatively poor action in treating symptomatic cystitis. The reason is that it is rapidly excreted and the duration of significant drug concentration in the urine is short. Also, they are relatively ineffective in clearing Gram-negative rods from the vaginal and colonic mucosa, thus possibly predisposing to recurrences when used to treat UTI. The susceptibility test of $K$. pnuemoniae showed that Nitrofurantoin and Ofloxacin had same activity (64.29\%) against the isolates as opposed to Gentamicin, Cefuroxime and Ceftazidime. This is similar, to previous studies in which Nitrofurantoin showed high efficacy followed by Co-trimoxazole, Tetracycline, Norfloxacin, Cephalexin, Pefloxacin, Cefaclor, Nalidixic acid, Ciprofloxacin [52] but $100 \%$ resistant to Amoxicillin and Ampicillin [29]. The low levels of resistance recorded on antibiotics such as ceftriaxone, nitrofurantoin and gentamycin seem to be as a result of accessibility and relatively high price compared to others. Thus, these drugs could be considered as alternative options in the empirical treatment of UTIs.

The susceptibility test of $P$. aeruginosa to the antibiotics used in this study showed that it was sensitive to Ceftazidime, Nitrofurantoin and Gentamicin. It however showed low susceptibility to the Fluoroquinolones, Ofloxacin (40\%) and Ciprofloxacin (20\%). Cefuroxime had an intermediate sensitivity of $60 \%$ against $P$. aeruginosa while resistance was observed with Amoxicillin/Clavulanate and Ampicillin (100\%). This result seems to agree with previous studies by Inam et al. [16] in which isolates were found to be sensitive to Carbapenems, amikacin, ceftazidime and antipseudomonal penicillin such as piperacillin. The test involving Proteus mirabilis showed that the isolates were highly sensitive (100\%) to Ofloxacin, Ciprofloxacin, Gentamicin and Ceftazidime with intermediate sensitivity to Cefuroxime, Nitrofurantoin but resistant (100\%) to Amoxicillin/Clavulanate and Ampicillin. This is also in agreement with previous study in Sukkur city where Ofloxacin and Ciprofloxacin demonstrated effectiveness against Escherichia spp, Klebsiella spp and Proteus spp [18]. The high-level susceptibility to Ciprofloxacin might not be unconnected to it high cost. This high cost has probably restricted its procurement and misuse by the residents investigated, thereby reducing emergence of resistant bacterial strains [41]. Similarly, the reason for high resistance of bacteria isolates to some antibiotics such as Ampicillin, Amoxycillin would probably be an earlier exposure of the isolates to these drugs, which may have enhanced resistant development [53]. 


\section{Conclusion}

The study revealed Staphylococcus aureus, among other organisms isolated, as the leading cause of UTI in the study environment. Amoxicillin/Clavulanate, Ofloxacin or Cloxacillin can be the drug of choice in the treatment of UTI due to Staphylococcus aureus even though susceptibility to these antibiotics is more precise on individual basis. The isolates obtained from the urine samples in this study were resistant to Amoxicillin/Clavulanate, Ampicillin (Gram-negative organisms) and Ceftazidime and Erythromycin (Gram-positive organism). The fungal isolate present showed good susceptibility to Ketoconazole.

\section{Compliance with ethical standards}

\section{Acknowledgments}

The authors wish to thank the Department of Pharmaceutical Microbiology \& Biotechnology, Faculty of Pharmaceutical Sciences, University of Port Harcourt, Nigeria for the permission to use some of her facilities for this research work.

\section{Disclosure of conflict of interest}

The authors declare that the research was conducted in the absence of any commercial or financial relationships that could be construed as a potential conflict of interest.

\section{Statement of ethical approval}

The study was approved by the research and ethics committee of University of Port Harcourt Teaching Hospital Rivers State, Nigeria.

\section{Statement of informed consent}

Informed consent was obtained from all individual participants included in the study.

\section{References}

[1] Krzyzaniak SM. (2011). Urinary tract infection: cystitis, pyelonephritis, and prostatitis. In: Emergency Medicine Secrets (Fifth Edition). Edited by Pons PT, Bakes KM. Saint Louis: Mosby, 270-275.

[2] Feld LG and Mattoo TK. (2010). Urinary tract infections and vesicoureteral reflux in infants and children. Pediatrics in Review, 31(11), 451-463.

[3] Mody L and Juthani-Mehta M. (2014). Urinary Tract Infections in Older Women: A Clinical Review. JAMA, 311(8), 844-854.

[4] Karlowsky JA, Kelly LJ, Thornsberry C, Jones ME and Sahm DF. (2002). Trends in antimicrobial resistance among urinary tract infection isolates of Escherichia coli from female outpatients in the United States. Antimicrobial Agents and Chemotherapy, 46(8), 2540-2545.

[5] De Backer D, Christiaens T, Heytens S, De Sutter A, Stobberingh EE and Verschraegen G. (2008). Evolution of bacterial susceptibility pattern of Escherichia coli in uncomplicated urinary tract infections in a country with high antibiotic consumption: a comparison of two surveys with a 10 year interval. Journal of Antimicrobial and Chemotherapy, 62(2), 364-368.

[6] Valiquette L. (2001). Urinary tract infections in women. The Canadian Journal of Urology, 8(1), 6-12.

[7] Stamatiou C, Bovis C, Panagopoulos P, Petrakos G, Economou A and Lycoudt A. (2005). Sex-induced cystitis-patient burden and other epidemiological features. Clinical and Experimental Obstetrics \& Gynecology, 32(3), 180-182.

[8] Medina-Bombardo D, Segui-Diaz M, Roca-Fusalba C and Llobera J. (2003). What is the predictive value of urinary symptoms for diagnosing urinary tract infection in women? Family Practice, 20(2), 103-107.

[9] Bent S, Nallamothu BK, Simel DL, Fihn SD and Saint S. (2002). Does this woman have an acute uncomplicated urinary tract infection? JAMA, 287(20), 2701-2710. 
[10] Ramesh N, Sumathi CS, Balasubramanian V, Ravichandran KP and Kannan VR. (2008). Urinary Tract Infection and Antimicrobial Susceptibility Pattern of Extended Spectrum of Beta Lactamase Producing Clinical Isolates. Advances in Biological Research, 2(5-6), 78-82.

[11] Kothari A and Sagar V. (2008). Antibiotic resistance in pathogens causing community-acquired urinary tract infections in India: a multicenter study. Journal of Infection in Developing Countries, 2(5), 354-358.

[12] Adeleke SI and Asani MO. (2009). Urinary tract infection in children with nephrotic syndrome in Kano, Nigeria. Annals of African medicine, 8(1), 38-41.

[13] Kolawole AS, Kolawole OM, Kandaki-Olukemi YT, Babatunde SK, Durowade KA and Kolawole CF. (2009). Prevalence of Urinary Tract Infections (UTI) among patients attending Dalhatu Araf Specialist Hospital, Lafia, Nasarawa State, Nigeria. International Journal of Medicinal Medical Sciences, 1(5), 163-167.

[14] Nwanze PI, Nwaru LM, Oranusi SU, Dimkpa U, Okwu MU, Babatunde BB, Anake TA, Jatto W and Asagwara CE. (2007). Urinary Tract Infection in Okada village: Prevalence and Antimicrobial Susceptibility Pattern. Scientific Research and Essays, 2(4), 112-116.

[15] Kashef N, Djavid GE and Shahbazi S. (2010). Antimicrobial susceptibility patterns of community-acquired uropathogens in Tehran, Iran. Journal of Infection in Developing Countries, 4(4), 202-206.

[16] Khan IU, Mirza IA, Ikram A, Afzal A, Ali S, Hussain A, Fayyaz M and Ghafoor T. (2014). Antimicrobial susceptibility pattern of bacteria isolated from patients with urinary tract infection. Journal of the College of Physicians and Surgeons Pakistan, 24(11), 840-844.

[17] Zaria LT, Raufu IA and Mohammed HS. (2010). Isolation and antibiotic sensitivity of Escherichia coli from pregnant and non-pregnant women attending the University of Maiduguri Teaching Hospital (UMTH), Maiduguri, Nigeria. International Journal of Biomedical and Health Science, 6(3), 159-164.

[18] Memon B. (2007). Predominant and Common cause of Urinary tract infection(s) in Sukkur city. Thesis, Shah Abdul Latif University Khairpur, Pakistan, 1-8.

[19] Wilson ML and Gaido L. (2004). Laboratory diagnosis of urinary tract infections in adult patients. Clinical infectious diseases: an official publication of the Infectious Diseases Society of America, 38(8), 1150-1158.

[20] Uwaezuoke JC and Ogbulie JN. (2006). Antibiotic Sensitivity Pattern of Urinary Tract Pathogens in Port-Harcourt, Nigeria. Journal of Applied Sciences and Environmental Management, 10(3), 103-107.

[21] Kahlmeter G. (2003). An international survey of the antimicrobial susceptibility of pathogens from uncomplicated urinary tract infections: the ECO. SENS Project. Journal of Antimicrobial Chemotherapy, 51(1), 69-76.

[22] Alemu A, Moges F, Shiferaw Y, Tafess K, Kassu A, Anagaw B and Agegn A. (2012). Bacterial profile and drug susceptibility pattern of urinary tract infection in pregnant women at University of Gondar Teaching Hospital, Northwest Ethiopia. BMC Research Notes, 5(1), 197.

[23] Acharya A, Gautam R and Subedee L. (2011). Uropathogens and their antimicrobial susceptibility pattern in Bharatpur, Nepal. Nepal Medical College Journal, 13(1), 30-33.

[24] Newell A, Riley P and Rodgers M. (2000). Resistance patterns of urinary tract infections diagnosed in a genitourinary medicine clinic. International Journal of STD \& AIDS, 11(8), 499-500.

[25] Prakash D and Saxena RS. (2013). Distribution and Antimicrobial Susceptibility Pattern of Bacterial Pathogens Causing Urinary Tract Infection in Urban Community of Meerut City, India. ISRN Microbiology, 1-13.

[26] Kahan NR, Chinitz DP, Waitman DA, Dushnitzky D, Kahan E and Shapiro M. (2006). Empiric treatment of uncomplicated urinary tract infection with fluoroquinolones in older women in Israel: another lost treatment option? The Annals of pharmacotherapy, 40(12), 2223-2227.

[27] Goldstein FW. (2000). Antibiotic susceptibility of bacterial strains isolated from patients with communityacquired urinary tract infections in France. Multicentre Study Group. European journal of clinical microbiology \& infectious diseases: Official Publication of the European Society of Clinical Microbiology, 19(2), 112-117.

[28] Manges AR, Natarajan P, Solberg OD, Dietrich PS and Riley LW. (2006). The changing prevalence of drug-resistant Escherichia coli clonal groups in a community: evidence for community outbreaks of urinary tract infections. Epidemiology and Infection, 134(2), 425-431. 
[29] Beyene G and Tsegaye W. (2011). Bacterial uropathogens in urinary tract infection and antibiotic susceptibility pattern in Jimma University specialized hospital, South West Ethiopia. Ethiopian Journal of Health Sciences, 21(2), 141-146.

[30] Fallon D, Andrews N, Frodsham D, Gee B, Howe S, Iliffe A, Nye KJ and Warren RE. (2002). A comparison of the performance of cystine lactose electrolyte deficient (CLED) agar with Oxoid chromogenic urinary tract infection (CUTI) medium for the isolation and presumptive identification of organisms from urine. Journal of Clinical Pathology, 55(7), 524-529.

[31] Cheesbrough M. (2002). Biochemical tests to identify bacteria. Laboratory Practice in Tropical Countries, Cheesbrough M (eds) Cambridge edn, 63-70.

[32] Stamdards A. (2010). Performance standards for antimicrobial susceptibility testing. Approved Standards CLSI, M100-S120.

[33] Akortha EE and Ibadin OK. (2008). Incidence and antibiotic susceptibility pattern of Staphylococcus aureus amongst patients with urinary tract infection (UTI) in UBTH Benin City, Nigeria. African Journal of Biotechnology, $7(11), 1637-1640$.

[34] Akerele J and Ahonkhai A. (2000). Urinary pathogen and antibacterial susceptibility. A retrospective study of private diagnostic laboratory in Benin City Nigeria. Journal of Medical Laboratory Science, 9, 47-48.

[35] Sule OAO. (1991). Bacterial flora of surgical wounds. Tropical Journal of Obstetrics and Gynaecology, $9(2), 41$.

[36] Abdul IF and Onile BA. (2001). Bacterial Isolates from the Urine of Women in Ilorin and their Antibiotic Susceptibility Patterns. Tropical Journal of Obstetrics and Gynaecology, 18(2), 61-65.

[37] Audu BM and Kudi AA. (2004). Microbial isolates and antibiogram from endocervical swabs of patients with pelvic inflammatory disease. Journal of Obstetrics and Gynaecology: the journal of the Institute of Obstetrics and Gynaecology, 24(2), 161-164.

[38] Onifade AK, Omoya FO and Adegunloye DV. (2005). Incidence and control of urinary tract infections among pregnant women attending antenal clinics in government hospitals in Ondo State, Nigeria. Journal of Food, Agriculture and Environment, 3(1), 37-40.

[39] Okonofua FE. (1995). The use of antibiotics in obstetrics and gynecology. Tropical Journal Obstretrics and Gynaecology, 12, 42-45.

[40] Olowu WA and Oyetunji TG. (2003). Nososcomial significant bacteriemia: prevalence and patterns of bacterial pathogens among children hospitalized for non-infecturing urinary tract disease. West African Journal of Medicine, 22(1), 72-74.

[41] Ehinmidu JO. (2003). Antibiotics susceptibility patterns of urine bacterial isolates in Zaria, Nigeria. Tropical Journal of Pharmaceutical Research, 2(2), 223-228.

[42] Richards MJ, Edwards JR, Culver DH and Gaynes RP. (1999). Nosocomial infections in medical intensive care units in the United States. National Nosocomial Infections Surveillance System. Critical Care Medicine, 27(5), 887-892.

[43] Krcmery S, Dubrava M and Krcmery V. (1999). Fungal urinary tract infections in patients at risk. International Journal of Antimicrobial Agents, 11(3), 289-291.

[44] Esan CO, Famurewa O, Lin J and Shittu A. (2009). Characterization of Staphylococcus aureus isolates obtained from health care institutions in Ekiti and Ondo States, South-Western Nigeria. African Journal of Microbiology Research, 3, 962-968.

[45] Egah DZ, Bello CS and Betal S. (1999). Antimicrobial susceptibility pattern of Staphylococcus aurues in Jos Nigeria. Journal of Medicine, 8(2), 58-60.

[46] Shittu SO and Mandere MU. (1999). Asymotomatic Bacteriuria in Antenatal Patients in Amadu Bello University Teaching Hospital, Zaria. Tropical Journal of Obstetrics and Gynaecology, 16(1), 41.

[47] Sardar A, Basireddy SR, Navaz A, Singh M and Kabra V. (2017). Comparative Evaluation of Fosfomycin Activity with other Antimicrobial Agents against E.coli Isolates from Urinary Tract Infections. Journal of Clinical and Diagnostic Research (JCDR), 11(2), Dc26-dc29.

[48] Warren JW, Abrutyn E, Hebel JR, Johnson JR, Schaeffer AJ and Stamm WE. (1999). Guidelines for antimicrobial treatment of uncomplicated acute bacterial cystitis and acute pyelonephritis in women. Infectious Diseases 
Society of America (IDSA). Clinical infectious diseases: an official publication of the Infectious Diseases Society of America, 29(4), 745-758.

[49] Dromigny JA, Nabeth P and Perrier Gros Claude JD. (2002). Distribution and susceptibility of bacterial urinary tract infections in Dakar, Senegal. International Journal of Antimicrobial Agents, 20(5), 339-347.

[50] Lau SM, Peng MY and Chang FY. (2004). Resistance rates to commonly used antimicrobials among pathogens of both bacteremic and non-bacteremic community-acquired urinary tract infection. Journal of Microbiology, Immunology, and Infection, 37(3), 185-191.

[51] Gupta N, Kundra S, Sharma A, Gautam V and DR A. (2007). Antimicrobial Susceptibility of Uropathogens in India. Journal of Infectious Disease and Antimicrobial Agents, 24(1), 13-18.

[52] Shaifali I, Gupta U, Mahmood SE and Ahmed J. (2012). Antibiotic susceptibility patterns of urinary pathogens in female outpatients. North American Journal of Medical Sciences, 4(4), 163-169.

[53] Krumperman PH. (1983). Multiple antibiotic resistance indexing of Escherichia coli to identify high-risk sources of fecal contamination of foods. Applied and Environmental Microbiology, 46(1), 165-170.

\section{How to cite this article}

Ezenobi NO, Ogbu HI and Onosigho I. (2018). Antimicrobial susceptibility pattern of urinary isolates from outpatients suspected for urinary tract infection. GSC Biological and Pharmaceutical Sciences, 5(3), 01-11. 